\title{
The Health and economic effects of light rail lines: design, methods, and protocol for a natural experiment
}

Lawrence D. Frank ${ }^{1,3}$, Jennifer L. Kuntz², James E. Chapman¹, Eric H. Fox ${ }^{1}$, John F. Dickerson², Richard T. Meenan², Brian E. Saelens ${ }^{4}$, Deborah R. Young ${ }^{5}$, Janne Boone-Heinonen ${ }^{6}$ and Stephen P. Fortmann ${ }^{2^{*}}$ (D)

\begin{abstract}
Background: The health impacts of community design have been studied extensively over the past two decades. In particular, public transportation use is associated with more walking between transit stops and shops, work, home and other destinations. Change in transit access has been linked with physical activity and obesity but seldom to health outcomes and associated costs, especially within a causal framework. Health related fiscal impacts of transit investment should be a key consideration in major transit investment decisions.

Methods: The Rails \& Health study is a natural experiment evaluating changes in clinical measures, health care utilization and health care costs among Kaiser Permanente Northwest (KPNW) members following the opening of a new light rail transit (LRT) line in Portland, Oregon. The study is prospectively following 3036 adults exposed to the new LRT line and a similar cohort of 4386 adults who do not live close to the new line. Individual-level outcomes and covariates are extracted from the electronic medical record at KPNW, including member demographics and comorbidities, blood pressure, body mass index, lipids, glycosylated hemoglobin, and health care utilization and costs. In addition, participants are surveyed about additional demographics, travel patterns, physical activity (PA), and perceived neighborhood walkability. In a subsample of the study population, we are collecting direct measures of travel-related behavior-physical activity (accelerometry), global positioning system (GPS) tracking, and travel diaries-to document mechanisms responsible for observed changes in health outcomes and cost. Comprehensive measures of the built environment at baseline and after rail construction are also collected. Statistical analyses will (1) examine the effects of opening a new LRT line on chronic disease indicators, health care utilization, and health care costs and (2) evaluate the degree to which observed effects of the LRT line on health measures and costs are mediated by changes in total and transportation-associated PA.
\end{abstract}

Discussion: The results of the Rails \& Health study will provide urban planners, transportation engineers, health practitioners, developers, and decision makers with critical information needed to document how transit investments impact population health and related costs.

Keywords: Transportation, Light rail transit, Built environment, Active travel, Physical activity, Health care utilization, Environmental measurement methods

\footnotetext{
* Correspondence: Stephen.P.Fortmann@kpchr.org

${ }^{2}$ Center for Health Research, Kaiser Permanente Northwest, Oregon, Portland, USA

Full list of author information is available at the end of the article
}

(c) The Author(s). 2019 Open Access This article is distributed under the terms of the Creative Commons Attribution 4.0 International License (http://creativecommons.org/licenses/by/4.0/), which permits unrestricted use, distribution, and reproduction in any medium, provided you give appropriate credit to the original author(s) and the source, provide a link to the Creative Commons license, and indicate if changes were made. The Creative Commons Public Domain Dedication waiver (http://creativecommons.org/publicdomain/zero/1.0/) applies to the data made available in this article, unless otherwise stated. 


\section{Background}

Rates of overweight and obesity have steadily risen in the last half-century and obesity is now one of the largest modifiable health risk factors for numerous common diseases, including diabetes, hypertension, cardiometabolic disorders, cancer, asthma, depression, and musculoskeletal disorders. [1-9] Nearly three-quarters of U.S. adults are now overweight or obese and the expected future increase in obesity rates will lead to millions of additional cases of diabetes, cardiovascular disorders, and other associated diseases. $[2,10,11]$ These trends will also lead to marked increases in health care costs. [12] In turn, regular physical activity (PA) reduces the risks of obesity, diabetes, and associated disorders. $[1,13]$ The high prevalence of physical inactivity in the U.S. is a major cause of high chronic disease rates and results in a large population-attributable risk from physical inactivity. [14-16]

Because these health problems are partially attributable to sedentary lifestyles, a promising area of research is now focusing on measuring the health impacts of the built and natural environment where people live and work. Researchers are investigating the population-level health impacts of changes in travel patterns resulting from transportation investments and land use patterns or local "walkability," [1721] and have demonstrated that transportation investments, land use patterns, and access to open space can impact physical activity and obesity prevalence. [22-38]

Growing evidence of the role of community design and the built environment in stimulating an active lifestyle has led to an increase in environmental interventions intended to promote PA. [39] However, studies that examine the impact of these interventions have rarely captured objective measures of PA or assessed the relationship between built environment and health-related biomarkers such as body mass index (BMI), blood pressure, or glycemic control. [40-42] Available studies also do not capture the behavioral and personal factors within a possible "causal pathway" that may mediate the relationship between the built environment and health outcomes. Thus, detailed, longitudinal data are needed, first to fully establish the relationship between improvements in community design-including public transportation infrastructure-and objectively measured clinical health outcomes; second, to determine how behavioral factors, specifically changes in physical activity, influence and mediate this relationship; and finally, to understand the impact environmental interventions such as transit investments have on healthcare utilization and costs. This information will allow policymakers and other decision makers to best align limited infrastructure investment resources with their potential for improved population health and cost savings.

The Rails \& Health study is a longitudinal natural experiment that examines the impact of a major public transportation infrastructure improvement-the opening of a new light rail transit (LRT) line-on clinical health outcomes and health care utilization and costs. The study seeks to leverage unique and robust observational research data to advance our understanding of the multi-faceted impacts of large-scale transit investments on public health. This article describes in detail the Rails \& Health study design, including participant recruitment, an extensive objectively-measured and self-reported health and environmental data acquisition effort, measurement methods, and statistical analyses. We also present strategies used to establish consistent, participant-specific neighborhood environmental measures related to community walkability, access to destinations and services, and social contexts.

\section{Methods}

Rails \& Health study design overview

The primary aim of the Rails \& Health Study is to examine the impact of opening a new LRT line on chronic disease indicators, health care utilization, and health care costs. The case-control design compares 3036 adults who live near the rail line to 4386 adults with similar demographic characteristics who live in similar areas away from the rail line (Fig. 1). To address this aim, measures of health care utilization and costs for the three years before and three years after the line opened are extracted from the KPNW electronic medical record (EMR). Chronic disease indicators include blood pressure, BMI, lipids measured by non-HDL cholesterol, and glycosylated hemoglobin (HgbA1c).

The second aim of the study is to evaluate the degree to which the observed impact of the LRT line on chronic disease indicators and health care utilization and costs are mediated by changes in total and transportation-associated PA (Fig. 1). To address this question, we will analyze outcome data from a subset of 600 participants-including objectively measured metrics of PA gathered using accelerometry, global position system (GPS) tracking, and self-report travel diaries, as well as a transportation and neighborhood perceptions survey. Collecting objective built and micro-scale pedestrian environment measures will allow us to evaluate how that environment may influence changes in PA, clinical measures, and health care costs.

\section{Study setting}

The study evaluates the impact of the Portland-Milwaukie Light Rail Project, also known as the Orange Line, which opened in September 2015. The Orange Line is a 7.3-mile, 10-station addition to the 53-mile, 87-station Metropolitan Area Express (MAX) light rail system of the Tri-County Metropolitan Transportation District of Oregon (TriMet). TriMet is the public agency that operates mass transit in the Portland, Oregon metropolitan 


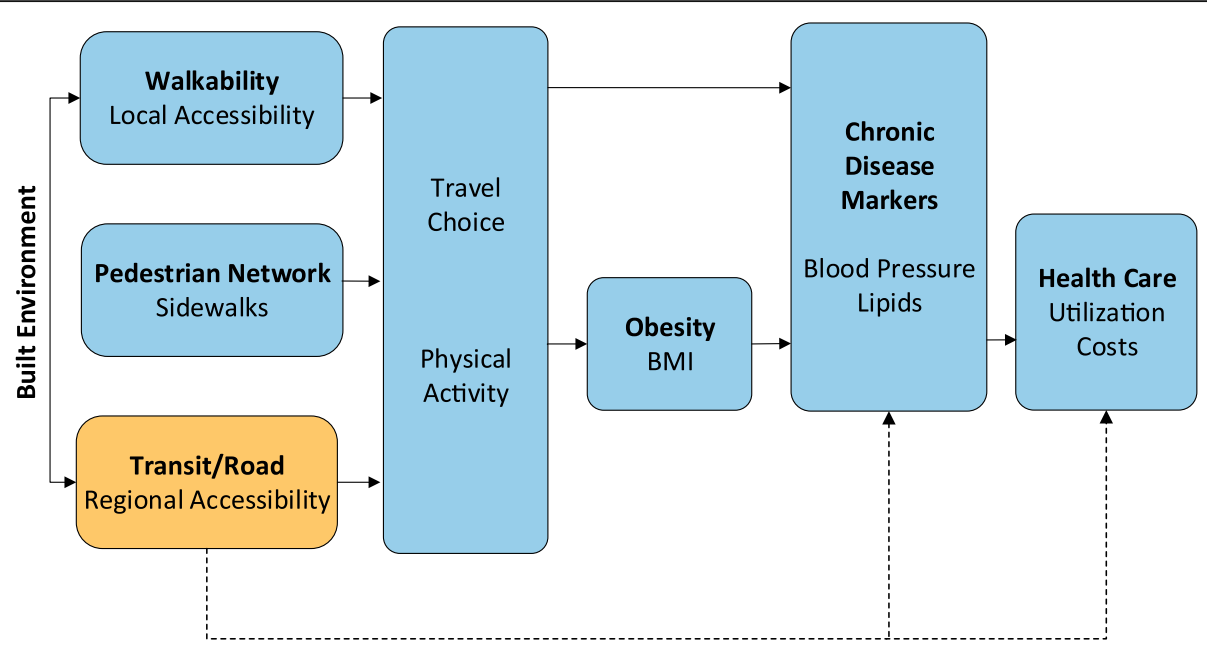

Fig. 1 Conceptual Model.@2019 Kaiser Permanente Center for Health Research

area. The new line connects downtown Portland to the City of Milwaukie, directly to the south, and includes the first multi-modal, car-free river bridge in the U.S. and concurrent improvements to pedestrian infrastructure within LRT station areas.

\section{Participants and recruitment}

Study participants are members of Kaiser Permanente Northwest (KPNW), an integrated health care system that provides ambulatory and hospital care to more than 600,000 patient-members in northwest Oregon and southwest Washington. Critical to this study, KPNW uses a comprehensive EMR, member addresses are updated frequently, and historical addresses are maintained.

\section{Overall cohort (aim 1)}

Participants in the overall cohort are aged 18-74 years and have lived at their current address for at least three years prior to the LRT line opening in September 2015. From among the pool of eligible participants, cases were identified as participants who had residential addresses in census block groups within a $1.5-\mathrm{km}$ road network buffer of one of the new LRT stations on the Orange Line (Fig. 2). Controls had residential addresses in census block groups with a similar baseline census median household income category and similar regional accessibility (defined by transit peak-hour travel time to downtown Portland) to cases. However, controls' block groups did not intersect a $1.5-\mathrm{km}$ road network buffer of any existing rail station. Residential address was the most recent address included in KPNW membership data. These data are updated and archived during almost every health care contact. The residence address of each participant was also geocoded to exact latitude and longitude and to the U.S. Census block, ZIP code, and county using a standard Geographic Information System (GIS) application. These were further validated using the Google Maps Application Programming Interface. Participant locations that were not precisely matched using the geocoded tool were investigated and manually adjusted to the actual physical address.

Demographic characteristics, clinical measures, and healthcare utilization data for members of the overall cohort are obtained through the KPNW EMR. Members of the overall cohort were also invited to complete an online survey regarding their transportation and neighborhood perceptions before September 2015. The invitation email contained a link to a survey website, which provided details about the research study and elicited consent for participation. Participants who completed this initial survey were asked to also complete a follow-up survey after the opening of the LRT line. Participants were entered into a drawing for a $\$ 100$ gift card each time they completed the survey.

\section{Behavioral cohort (aim 2)}

A subset of the overall cohort-600 members- was recruited and asked to collect objective PA and travel patterns over two seven-day periods: prior to and one year after the opening of the LRT line. This data collection included completion of a travel diary and PA monitoring using an accelerometer and GPS device. All participants in this "behavioral cohort" also completed the online transportation and neighborhood perceptions survey.

To recruit this subset of participants, we stratified cases into four categories based on how distant each case's residence was from an LRT station. Recruitment of cases started in block groups immediately adjacent to each Orange Line station and worked outward until the LRT line opened, ending the recruitment window. Controls were recruited by randomly selecting members 


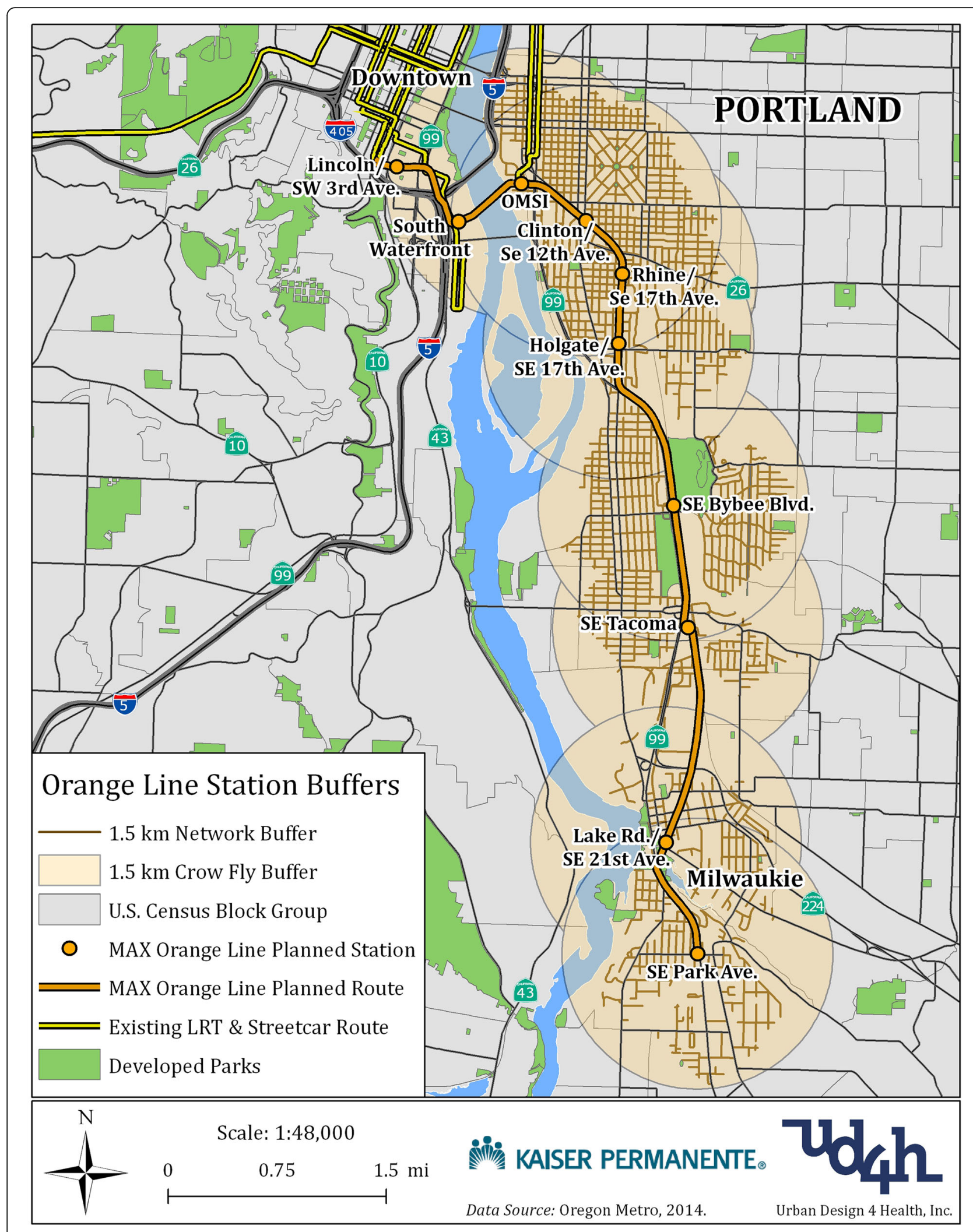

Fig. 2 Map illustrating 1.5-km walkable road network and "crow-fly" proximity buffers around MAX Orange Line station areas used for participant recruitment.@2019 Urban Design 4 Health, Inc. 
from the matched control block groups. Potential participants were sent an introductory email with a description of the study and a link to the online survey, and then were contacted by telephone. During the telephone call, study staff explained the study procedures, confirmed the participant's current address, and obtained verbal consent for initial and follow-up data collection. Participants were then mailed a paper copy of the consent document, the accelerometer and GPS devices, a paper travel diary, written instructions, and materials for returning the devices and travel diary. All participants received a follow-up phone call after receiving the study materials to explain how to use the devices, answer questions, and encourage study completion. Participants who completed all data collection at both time points received a $\$ 75$ gift card.

\section{Data collection}

Table 1 includes an overview of study data collection for the overall cohort and the behavioral cohort. We collected EMR data for all participants, data from a transportation and neighborhood perceptions survey for a subset of the overall cohort and all members of the behavioral cohort, and detailed transportation and activity data from the behavioral cohort. Additionally, we constructed comprehensive measures to describe the macro scale (walkability) and micro scale (pedestrian) environment of participants' neighborhoods. Pedestrian environments were assessed for both home and work locations for the behavioral cohort.

The Kaiser Permanente Northwest Institutional Review Board reviewed and approved all study procedures and materials. Informed consent and Health Insurance Portability and Accountability Act authorization were waived for EMR data collection. Participants who completed surveys provided consent at the time of survey initiation after reading the consent language, while participants undergoing behavioral data collection provided verbal consent and authorization. Because we used telephone recruitment and remote data collection (no direct visit), signed consent was waived for the behavioral cohort.

\section{Electronic medical record-derived measurements}

All demographic and clinical covariate data, clinical outcome data, and health care utilization data were extracted directly from the KPNW EMR (an instance of Epic'). These measures were collected for the overall cohort for the three years before and after the LRT line opened.

The clinical outcomes for the primary study aim obtained from EMR laboratory and encounter data are blood pressure, BMI, non-HDL cholesterol, and HgbA1c. Health care utilization is collected from EMR encounter data and includes average monthly outpatient visits, average monthly length of inpatient stays, and average total monthly medication utilization. Pharmacy dispensing data are also collected from the EMR since KPNW includes a closed pharmacy benefit. Health care costs are calculated using a Standardized Medical Care Costing Model developed at the Center for Health Research to account for all services, procedures, and products received by a member, as captured in the KPNW data systems. [43] Demographic data collected from the EMR include birthdate (age) and self-reported sex, race, and ethnicity. Income and education data are not complete in the EMR, so census-derived values were used. Clinical covariate data included history of smoking and alcohol use and the presence of chronic diseases and comorbidities, identified through diagnosis codes assigned during health care encounters and aggregated using the Charlson Comorbidity Index. [44]

\section{Transportation and neighborhood perceptions survey}

The transportation and neighborhood perceptions survey collected additional information about transportation use, perceived PA, and perceived neighborhood characteristics prior to and after the opening of the LRT line (survey available from the authors). These data will be used in descriptive analyses and as covariates in models that examine whether potential changes in clinical, utilization, and cost outcomes related to the LRT line are impacted by PA and transit use. The survey includes self-report measures of: (1) demographics, including income, education, race, ethnicity and social habits (e.g., smoking, alcohol use); (2) physical functioning, or functional status, as measured through a validated 10-item short form recommended by the $\mathrm{NIH}$ Patient-reported outcomes system (PROMIS) [45, 46]; (3) duration of residence prior to study enrollment and prior three addresses; (4) preferences for pedestrian- and transit-oriented neighborhoods versus auto-oriented neighborhoods, measured through an established series of stated preference survey questions [47]; (5) perceived walkability of a participant's neighborhood, as measured through the abbreviated Neighborhood Environment Walkability Scale (NEWS-A) [48]; (6) typical travel behavior and travel modes to common destinations (e.g., work, shopping, recreation), travel times, costs, and factors affecting mode choices; (7) household factors that may influence PA, such as the presence of children, elderly dependents, pets, and exercise equipment; (8) perceptions and opinions about mass transit systems and use; and, (9) worksite environment, including a participant's primary worksite address and perceptions of worksite exercise and health promotion activities. $[49,50]$

\section{PA and transportation data collected from behavioral cohort} Accelerometry

Physical activity was objectively measured with GT3X+ accelerometers (Actigraph ${ }^{\circ}$, Pensacola, FL). The GT3X+ 
Table 1 Summary of Data Collection for Study Population Sub-groups

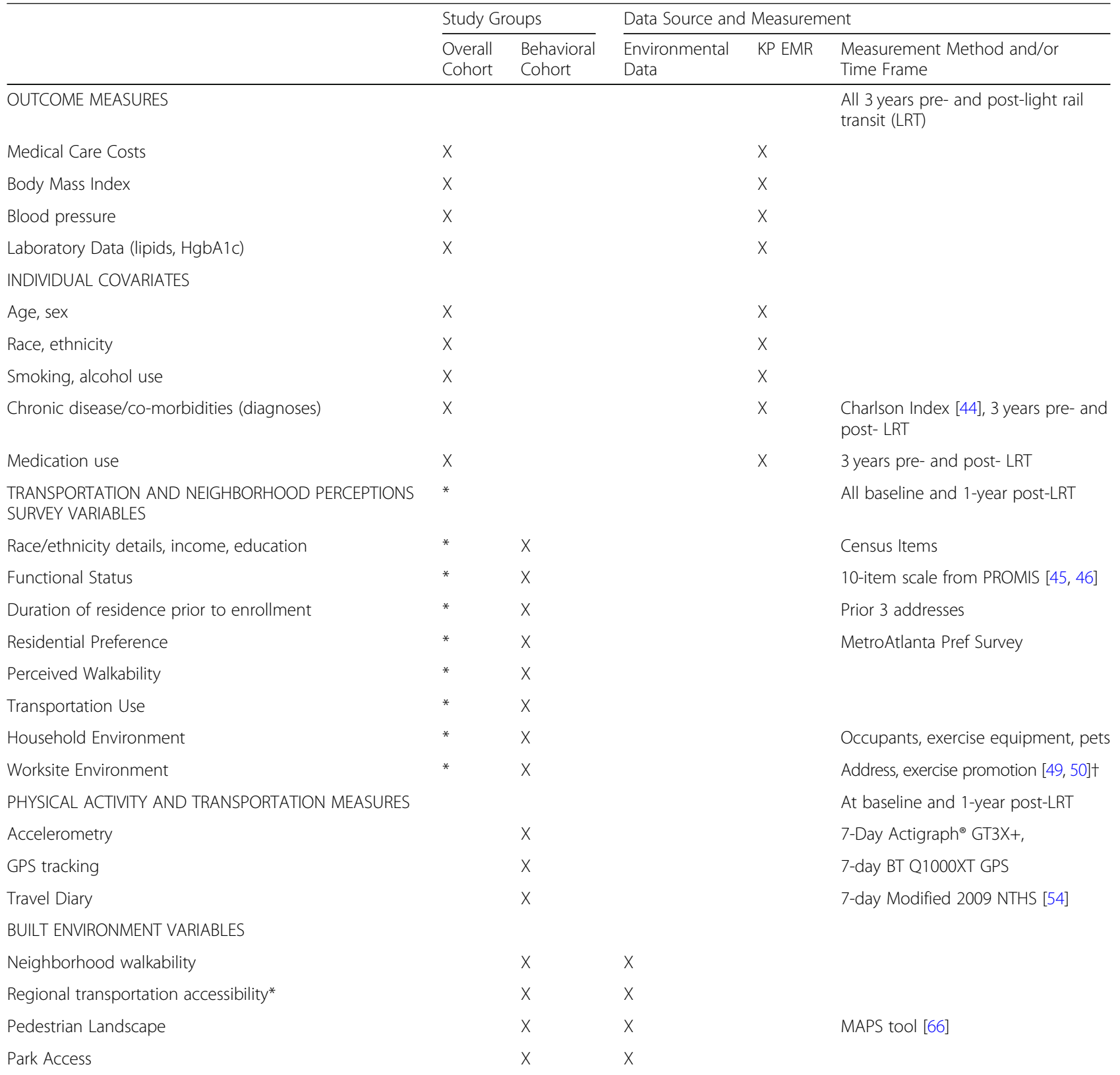

NOTE: Participants in the behavioral cohort are included in the overall cohort *For a subset of the overall cohort

is a triaxial monitor that detects acceleration in the vertical, anteroposterior, and mediolateral axes. [51] Participants were asked to wear a monitor during all waking hours for seven consecutive days, and also to record times when they were not wearing the monitor. Accelerometry data were collected and stored in 15-s intervals. The data were categorized into physical activity bouts, defined as time intervals having $>500$ accelerometer counts per 30-s epoch (cpe) for at least seven minutes, allowing for up to two minutes of epochs below that threshold during the seven-minute interval. The threshold of 500 cpe was chosen to capture light PA that might be associated with slow walking at an average speed of $3 \mathrm{~km}$ per hour. $[52,53]$

\section{Global positioning system (GPS) monitoring}

Geographic position and instantaneous movement speed provide contextual information about PA behaviors such as the location of an activity and the mode of transportation. These data were collected using the BT Q1000XT 
GPS Travel Recorder (QStarz, Taipei, Taiwan). Participants were asked to wear or carry the portable travel recorder for seven days, concurrent with accelerometer use and travel diary data collection. The device can be attached to the accelerometer belt or another belt and works up to twenty hours when set at 15-s epoch acquisition.

\section{Travel diary}

Participants in the behavioral cohort also completed a written travel diary for each day of accelerometer and GPS wear. The travel diary is based on the $2009 \mathrm{Na}$ tional Highway Transportation Survey, with additional questions about recreational travel. [54] Participants are instructed to log departure and arrival locations and times, travel mode, trip purpose, and destination activities for all trips made within the 7-day period. [55]

\section{Integration of accelerometer, GPS, and travel diary data}

Data from the GPS and accelerometer units were cleaned, processed, and merged using the All-in-one Spatial Activity Processor, an open source tool developed by researchers at Portland State University. [56] The tool identifies erroneous GPS data points (e.g., unrealistic speed, distance traveled, or position) and smooths the data using automated and systematized procedures. [57] GPS records were also plotted using spatial GIS software and spot-checked to identify any other systematic errors.

Once GPS and accelerometer data were merged, discrete trips were differentiated using methods that examine speed variations and time spent at specific destinations. Travel mode (e.g. walking, biking, mass transit, automobile) was ascertained based on travel speed, route, and transportation network characteristics. [58] Individual trips and tours were constructed to capture travel between destinations. [59] Cluster detection methods were employed to identify points centered on a specific location and occurring over a period of at least $120 \mathrm{~s}$, which indicates a destination.

Travel diary information was entered into a database and algorithms were used to identify missing and possibly erroneous data prior to merging it with GPS and accelerometer data. Trip records were flagged for any of the following errors: trip ended before it started; trip departed before the preceding trip arrived; trip spanned more than $12 \mathrm{~h}$. Research staff contacted participants as needed to fill in missing entries or to clarify erroneous entries.

Merged accelerometer and GPS data were then joined to travel diary data by matching the arrival/departure times from the travel diary with the closest time stamp in the merged GPS and accelerometer data. Collectively, the data integration allows for validation of behaviors across data streams, provides additional information for data cleaning and imputation, and facilitates the derivation of summary PA metrics.

\section{Measures of built environment}

We derived comprehensive measures of the built environment for each participant's residence and workplace address at baseline. We will test how these measuresincluding neighborhood walkability; regional accessibility to destinations; seating, lighting, sidewalks, and other design features; and access to open space, moderate the effect of the LRT line opening on PA, clinical health measures, and costs.

\section{Pedestrian-enhanced walkable road network}

As a formative step in the creation of built environment measures, we assembled a comprehensive network that pedestrians can traverse, including roadways and non-motorized, multi-use pathways. This walkable network was used for three primary purposes: (1) defining the catchment area a participant can walk to within a given distance (street network buffer) from their home and their work, (2) determining the locations of intersections and cul-de-sacs, and (3) determining the network distance and walking travel times, from a participant's home and work, to the nearest work and non-work destinations.

We acquired a road centerline file and information describing pedestrian and cyclist non-motorized pathways from Metro, the metropolitan planning organization serving the Portland Region. [60] All road types where pedestrians are not permitted-including interstates, freeways, and other limited access ramps and interchanges-were removed to create a "walkable road network." Non-motorized facilities such as regional and local trails, park pathways, and cul-de-sacs/dead-end cut throughs were also included (Fig. 3).

\section{Regional accessibility}

Regional accessibility measures relative travel time and distance, by location and mode, to major, regionally-significant destinations. It is derived from regional travel demand models used to inform transportation investment decisions and is based on the trip distribution sub-model that predicts where people will go for given types of trips. It captures access to jobs, parks, shops, and other destinations within a given amount of time. The study used locations of regional significance defined by the Metro 2040 Growth Concept. [60] These locations were considered to be the most important regional centers and were targeted for concentrated future growth.

The measures of regional accessibility included the network distance and estimated travel times (for both single occupancy vehicles and on transit) between all participant origin locations and regionally significant destinations, as well as an average measure of the network distance to 


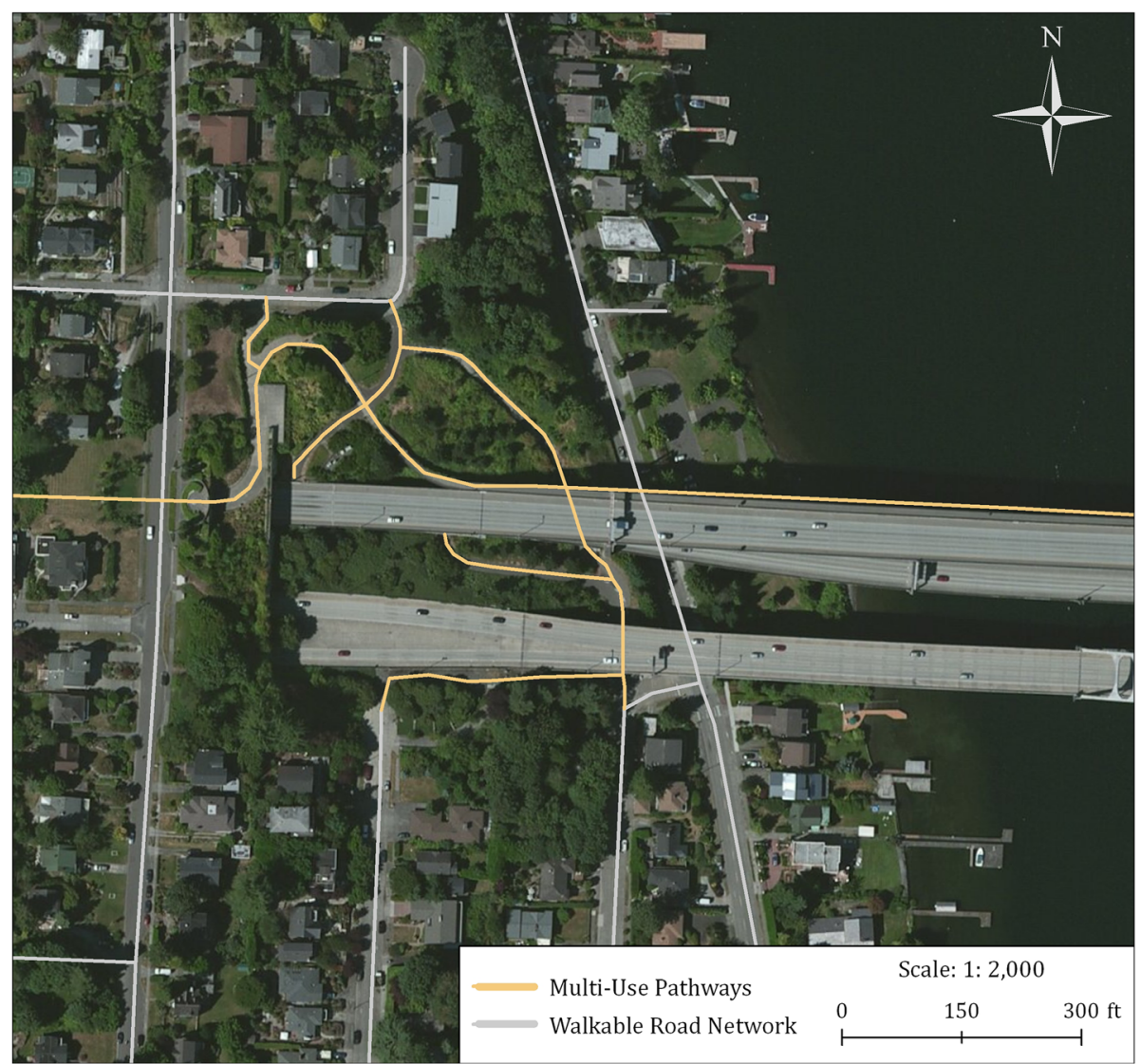

Fig. 3 Example section of the "pedestrian-enhanced" walkable road network that excludes freeway road segments while integrating multi-use pathways.@2019 Urban Design 4 Health, Inc

these destinations. Auto travel time estimates were obtained from Metro using their modeled "centroid based" zone to zone travel times from the regional travel demand model. Zone to zone private vehicle travel times reflect actual or "congested" travel speeds for peak and off-peak periods. Transit travel time estimates for peak and off-peak (including walking to and from the transit system) were calculated using General Transit Feed Specification transit schedule data (GTFS Data Exchange: http://transitfeeds.com).

\section{Walkability}

Walkability combines measures of proximity (density and land use mix), street connectivity or route directness, and retail floor area ratio or street setback, forming a composite measure of local accessibility. Walkability is a validated construct that captures variations in development patterns that are associated with behavior, including travel and PA. We focused on walkability variables that most influence choices about transportation mode (e.g., driving vs. walking). [61]

\section{Participant network buffers}

Spatial catchment areas, referred to here as buffers, originating at a participant's home or work address, capture the area a participant can access on the road network for a given distance. State of the art "sausage" based network buffers (see Fig. 4) were developed to delineate areas within a $1-\mathrm{km}(0.6$ mile) walk distance, with a $25-\mathrm{m}(82 \mathrm{ft})$ trim or setback from the roadway. [42, 62-64] The sausage buffer first defines the catchment area along a 1-km distance in all directions on the network. The 25-m trim distance from the road network removes areas not accessible to pedestrians set back from the road network. Our sausage buffer design also supports specific requirements of each built environment measure. For example, it nets out non-residential areas to create the land area denominator for calculating net density measures (see Fig. 4).

\section{Pedestrian landscape}

The Microscale Audit of Pedestrian Landscape (MAPS) tool is used to quantify microscale characteristics of street segments shown to have relevance for walking and 

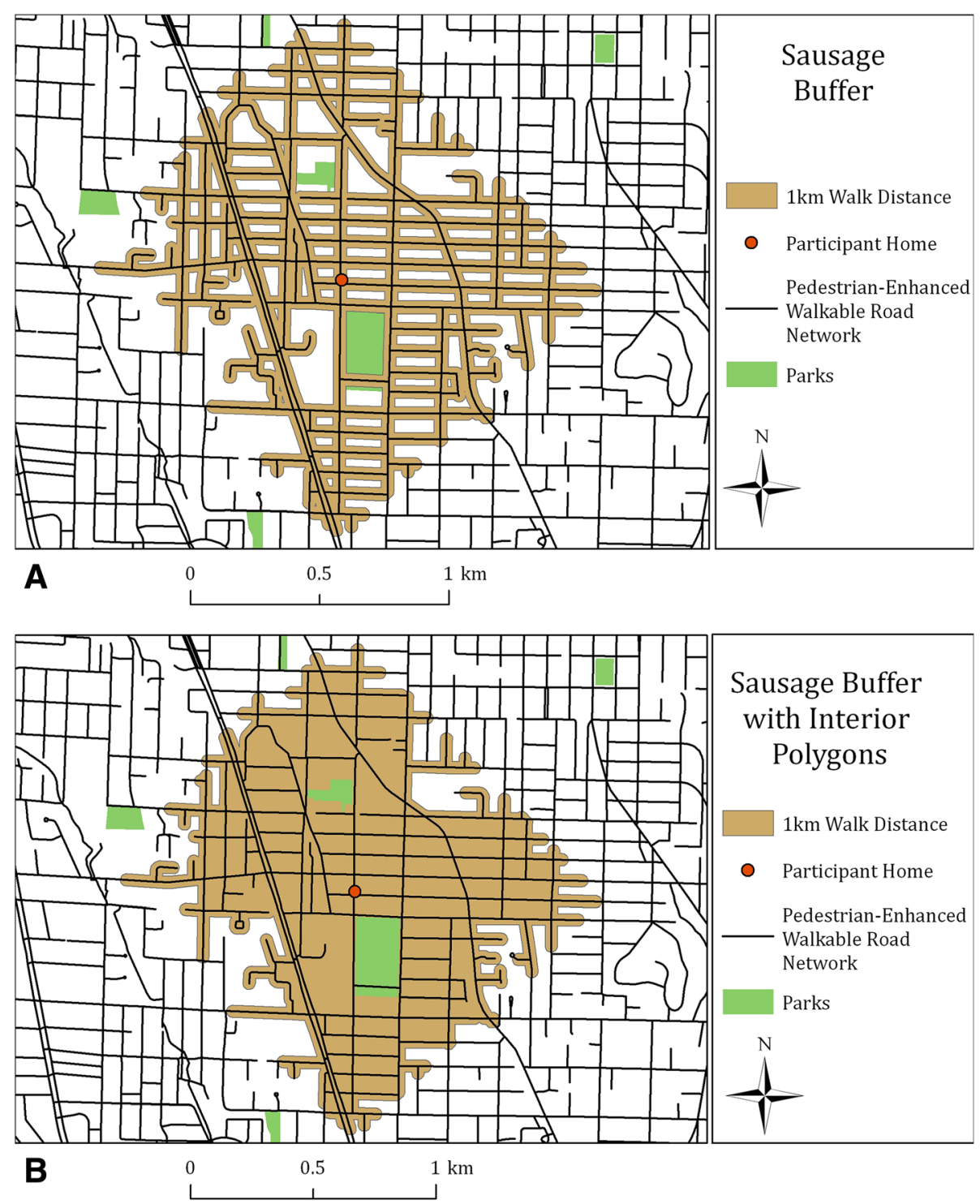

Fig. 4 Buffer comparison showing the "sausage" or balloon buffer and the same buffer combined with the interior or island polygons. Image A is the buffer form used to calculate all built environment variables including counts and intersecting features. The area derived from the Image B form was used as the denominator for all density measures.@2019 Urban Design 4 Health, Inc

other forms of PA. [65] Routes between home and work for each participant were characterized using the MAPS tool. [66, 67] The MAPS tool accounts for a variety of street design features, including speed limit, sidewalk quality, land use, transit service, street crossing environment, bike facilities, landscaped buffers, building characteristics, crosswalks, crossing width, and signalization. [68] Based on these features, the tool provides distinct scores for overall route, street segments, intersections, and cul-de-sacs. Overall, 47 route-related variables, 24 segment-related variables, 21 crossing-related variables, and six cul-de-sac-related variables were assessed and aggregated into 11 subscale, overall, and cross-sectional variables based on expert consensus, theoretical assumptions of how the built environment influences physical activity, and policy-relevant considerations. [69]

\section{Park environment}

Public parks offer residents opportunities for physical activity among other health benefits. We counted the number of parks and calculated total park area intersecting and accessible within the 1-km sausage buffer around each participant's residence and work location, as well as the distance from each residence and work location to the nearest park. We included only developed, public parks with regular municipal maintenance, excluding natural areas not meant for regular access by the public and private areas such as golf courses. We separated parks into 
three size categories: (1) small park, parklet, or pocket park (<1 acre), (2) medium park (1-50 acres), and (3) large park or state park (> 50 acres).

\section{Crime}

Crime is a significant factor impacting the perceived safety and comfort of walking in a neighborhood. Crime data were obtained from the uniform incident reporting system used by the Portland Bureau of Police tracking all crime offenses. Crimes were separated into violent and non-violent. Violent crime consisted of homicide, rape, aggravated assault, kidnapping, robbery and arson with all remaining crimes identified as non-violent, including motor vehicle theft, fraud, prostitution, driving under the influence and drug related incidents. Geographic locations of each crime incident were plotted and the counts of crime incidents within each participant's home and work buffer were summed to provide a measure of neighborhood crime.

\section{Statistical analyses plan \\ Aim 1 analyses}

Our first aim is to assess the impact of the LRT line opening on clinical health outcomes, health care utilization, and health care costs from three years before to three years after the line opened. These analyses include participants in the overall cohort who have at least four outcome measures over the entire six-year period, with at least one of each measure occurring prior to and after the LRT line opening.

\section{Clinical health outcomes}

Multilevel modeling will be used to determine the effect of the LRT line opening on clinical health measures including blood pressure, BMI, blood lipids, and HbgA1c. Time will form the first level of the model and all available measurements for each participant will be included. Person will form the second level of the model that will include person-level covariates of age, sex, and comorbid conditions measured at the earliest available time point. Since people are nested within block group, block group will form the third level of the model with a dummy variable for case versus control block group. This model will estimate a trajectory of the outcomes over time for each participant and will examine differences in trajectory based on case or control status.

\section{Health care utilization and costs}

Segmented regression analysis will be used to compare trends in health care utilization and costs for case and control groups before and after the LRT line opening. Ultimately, this method allows us to statistically assess how much the introduction of the LRT line changed health care utilization and cost immediately and over time; transiently or persistently; and instantly or with delay. Specifically, we will perform a basic segmented regression analysis in which the overall six-year time period is divided into pre- and post-intervention segments. For each segment, separate intercepts and slopes will be estimated, thus allowing for statistical tests of changes in intercepts and slopes pre- to post-intervention. Statistical power will be enhanced if we find stable pre-intervention trends in the dependent variable of interest. We will use month as the unit of analysis (36 months pre- and 36 months post-LRT introduction). Health care utilization and cost measures will include average monthly outpatient visits and costs, average monthly inpatient length of stays and cost, average total monthly medication cost, and average total monthly health care expenditures.

\section{Aim 2 analyses}

Structural equation modeling (SEM) will be used to determine the degree to which changes in clinical outcomes and health care costs are mediated by changes in total and transportation-associated PA (measured through accelerometer, GPS, and travel diary data), when controlling for built environment measures such as walkability and measures of pedestrian and recreational infrastructure. SEM allows us to test the relationships among the variables simultaneously. To accomplish this, change scores from the first time point ( $2-3$ years prior to the opening of the LRT line) to the last time point (2-3 years after the opening) for all variables will be examined. To test for mediation, a multilevel structural equation modeling approach will be used. Potential moderators of the effect of the new rail line on health outcomes will also be explored. For example, the interaction between case or control status and variables such as age, sex, race/ethnicity, distance from home to station, baseline walkability, pedestrian network (as measured by the MAPS tool), and baseline functional status will be incorporated into multilevel models to test if the degree of impact of the new rail lines varies across the levels of these potential moderator variables.

\section{Sample size and power}

The sample size for this natural experiment was fixed and determined by the number of KPNW members who had residential addresses in census block groups within a $1.5-\mathrm{km}$ road network buffer of one of the new LRT stations. These cases were matched at the block group level to an equivalent number of members living outside of a $1.5-\mathrm{km}$ road network buffer of any existing rail station. During the planning phase of the study, the population anticipated to have sufficient data for our clinical outcomes - based on estimated variations in the data capture of clinical health outcome measurement and loss to follow-up - was 3050 participants for BMI and blood 
pressure; 2350 for blood lipids; and 850 for HbgA1c. The detectable changes between cases and controls for the main outcome measures were calculated with statistical power of 0.80 and an alpha level of 0.05 . The calculations of detectable differential change used means and standard deviations for the outcome measures as estimates of the baseline values, accounted for the correlation between individuals nested within block groups, and assumed no change in the control group. Given these parameters, we estimated that our study would detect significant differences between cases and controls if the change over time in the light rail group was $4 \%$ greater for BMI, $1.4 \%$ greater for BP, $2.8 \%$ greater for HgbA1c, and $2.4 \%$ greater for non-HDL cholesterol. These levels would be clinically significant at the population level.

For our analysis of healthcare costs, interrupted time series analyses are considered to have good statistical power if the trend prior to the system change is fairly stable. Similar segmented regression analyses have had adequate power to detect modest effects and were used to inform policy at the system level using data for 12 time points pre- and post-intervention. [70, 71] Our study captures six total years of healthcare cost data, or 72 time points, which provides adequate power.

\section{Discussion}

Recent cross-sectional evidence makes clear connections between built environment, activity patterns, and health outcomes; increasing levels of transit access and walkability are associated with increased physical activity and reduced levels of chronic disease. [72] These findings have been extended to health care costs using costs of illness methods in a few limited unpublished studies. [73] So far, no research has shown how clinically assessed, EMR-derived health outcomes and associated health care utilization and costs relate to the built environment. Further, no research we are aware of has directly connected built environment data with EMR data containing clinically assessed health outcomes and related costs within the framework of a longitudinal intervention designed to assess causation.

The methods we describe constitute a unique research design to better understand the potential causal impacts of transportation investments and land use on physical activity, obesity, and clinically assessed health outcomes and cost. The ability to connect multi-billion-dollar transportation investments with similarly-scaled, currently externalized health care costs holds considerable research promise. The results from this study and others that may build on it could have a major influence on transportation investment decision-making protocols. Cost-benefit tools currently used to justify transportation investments do not account for the health impacts and costs they incur, resulting in decisions that promote roadway improvements over transit and non-motorized investments. Internalizing these costs within the transportation investment process has the potential to better estimate the collective societal impacts of these major investments.

Sedentary and active travel choices are made based on the quality, convenience, and relative utility of available travel options. [74, 75] It can be argued that mode choice roughly follows the distribution of funding spent per mode over the past several decades. Mounting health care costs from chronic diseases within the context of an aging population warrant critical attention to underlying built environment factors that shape travel patterns and in turn impact population health.

The Rails \& Health study will provide information that documents how a new transportation option can alter PA, health, and health care costs over time. This study will provide valuable data and contribute unique methods. It may also present a compelling rationale for cost benefit-tools and empirically grounded health impact assessments. These approaches can collectively assess health outcomes and costs stemming from contrasting transportation investment and land development options.

\section{Abbreviations \\ BMI: Body Mass Index; EMR: Electronic Medical Record; GIS: Geographic Information System; GPS: Global Positioning System; KPNW: Kaiser Permanente Northwest; LRT: Light Rail Transit; MAPS: Microscale Audit of Pedestrian Streetscapes; PA: Physical Activity; SEM: Structural Equation Modeling; TriMet: Tri-County Metropolitan Transportation District of Oregon}

\section{Acknowledgements}

The authors gratefully acknowledge Kristine L. Funk, MS, RD, and Judy L. Donald for their project management and support during the preparation of this manuscript.

\section{Funding}

This study is funded by a grant from the National Institute of Diabetes and Digestive and Kidney Diseases, National Institutes of Health to Dr. Fortmann (R01 DK103385). The funder does monitor study progress, but does not have a role in the conduct of the study and did not contribute to the preparation of this manuscript

\section{Availability of data and materials}

Not applicable. This study is ongoing and no data are presented in this paper.

\section{Authors' contributions}

All authors made substantial contributions to the study conception and design. LDF, JLK, RTM, JFD, EHF, JEC, BES, DRY, JBH and SPF were all involved in drafting portions of the manuscript. All authors revised the manuscript critically for important intellectual content. All authors have given final approval of this manuscript version, take responsibility for content, and are accountable for all aspects of the work.

\section{Ethics approval and consent to participate}

The institutional review board of the KPNW Center for Health Research reviewed and approved all study procedures and materials. Informed consent and Health Insurance Portability and Accountability Act authorization were waived for EMR data collection in this study. Participants who completed surveys provided written consent at the time of survey initiation, while participants undergoing behavioral data collection provided verbal consent and authorization. Signed consent was waived for the 
behavioral cohort because the study is low-risk and used telephone recruitment and remote data collection (no direct visit).

\section{Consent for publication}

Not applicable.

\section{Competing interests}

The authors declare that they have no competing interests.

\section{Publisher's Note}

Springer Nature remains neutral with regard to jurisdictional claims in published maps and institutional affiliations.

\section{Author details}

${ }^{1}$ Urban Design 4 Health, Inc., Rochester, NY, USA. ${ }^{2}$ Center for Health Research, Kaiser Permanente Northwest, Oregon, Portland, USA. ${ }^{3}$ Health \& Community Design Lab, Schools of Population and Public Health and Community and Regional Planning, University of British Columbia, Vancouver, BC, Canada. ${ }^{4}$ Seattle Children's Research Institute and the University of Washington, Seattle, WA, USA. ${ }^{5}$ Center for Research \& Evaluation, Kaiser Permanente Southern California, Pasadena, CA, USA ${ }^{6}$ Oregon Health \& Science University, School of Public Health, Oregon, Portland, USA.

Received: 4 September 2018 Accepted: 6 February 2019 Published online: 15 February 2019

\section{References}

1. Gillett M, Royle P, Snaith A, Scotland G, Poobalan A, Imamura M, Black C, Boroujerdi M, Jick S, Wyness $L$, et al. Non-pharmacological interventions to reduce the risk of diabetes in people with impaired glucose regulation: a systematic review and economic evaluation. Health Technol Assess. 2012; 16(33):1-236.

2. Benjamin EJ, Blaha MJ, Chiuve SE, Cushman M, Das SR, Deo R, de Ferranti SD, Floyd J, Fornage M, Gillespie C, et al. Heart Disease and Stroke Statistics2017 Update: A Report From the American Heart Association. Circulation. 2017;135(10):e146-603. https://doi.org/10.1161/CIR0000000000000485 Epub 0000000000002017 Jan 0000000000000425.

3. Esser N, Legrand-Poels S, Piette J, Scheen AJ, Paquot N. Inflammation as a link between obesity, metabolic syndrome and type 2 diabetes. Diabetes Res Clin Pract. 2014;105(2):141-50. https://doi.org/10.1016/ jdiabres201410041006 Epub 2014 Apr 1013.

4. Singla P, Bardoloi A, Parkash AA. Metabolic effects of obesity: a review. World J Diabetes. 2010;1(3):76-88. https://doi.org/10.4239/wjd.v4231.i4233. 4276.

5. Huang Y, Cai X, Chen P, Mai W, Tang H, Huang Y, Hu Y. Associations of prediabetes with all-cause and cardiovascular mortality: a meta-analysis. Ann Med. 2014:46(8):684-92. https://doi.org/10.3109/ 078538900785201407955051 Epub 07852014 Sep 07853818

6. Guh DP, Zhang W, Bansback N, Amarsi Z, Birmingham CL, Anis AH. The incidence of co-morbidities related to obesity and overweight: a systematic review and meta-analysis. BMC Public Health. 2009;9:88. https://doi.org/10. 1186/1471-2458-1189-1188

7. Harriss DJ, Atkinson G, George K, Cable NT, Reilly T, Haboubi N, Zwahlen M, Egger M, Renehan AG. Lifestyle factors and colorectal cancer risk (1): systematic review and meta-analysis of associations with body mass index. Colorectal Dis. 2009;11(6):547-63. https://doi.org/10.1111/j1463$1318200901766 x$ Epub 02009 Jan 01717.

8. Gilliland FD, Berhane K, Islam T, McConnell R, Gauderman WJ, Gilliland SS, Avol E, Peters JM. Obesity and the risk of newly diagnosed asthma in school-age children. Am J Epidemiol. 2003;158(5):406-15.

9. Simon GE, Arterburn D, Rohde P, Ludman EJ, Linde JA, Operskalski BH, Jeffery RW. Obesity, depression, and health services costs among middleaged women. J Gen Intern Med. 2011;26(11):1284-90. https://doi.org/10. 1007/s11606-11011-11774-x Epub 12011 Jun 11628.

10. Flegal KM, Kruszon-Moran D, Carroll MD, Fryar CD, Ogden CL. Trends in Obesity Among Adults in the United States, 2005 to 2014. JAMA. 2016; 315(21):2284-91. https://doi.org/10.1001/jama.2016.6458.

11. Finkelstein EA, Khavjou OA, Thompson H, Trogdon JG, Pan L, Sherry B, Dietz W. Obesity and severe obesity forecasts through 2030. Am J Prev Med. 2012;42(6):563-70. https://doi.org/10.1016/j.amepre.2011.1010.1026.
12. Wang $Y$, Beydoun MA, Liang L, Caballero B, Kumanyika SK. Will all Americans become overweight or obese? estimating the progression and cost of the US obesity epidemic. Obesity (Silver Spring). 2008;16(10):2323-30. https:// doi.org/10.1038/oby20082351 Epub 2008 Jul 2324.

13. Reiner M, Niermann C, Jekauc D, Woll A. Long-term health benefits of physical activity--a systematic review of longitudinal studies. BMC Public Health. 2013;13:813. https://doi.org/10.1186/1471-2458-1113-1813.

14. Durstine JL, Gordon B, Wang Z, Luo X. Chronic disease and the link to physical Activity. J Sport Health Sci. 2013;2(1):3-11.

15. Bauer UE, Briss PA, Goodman RA, Bowman BA. Prevention of chronic disease in the 21st century: elimination of the leading preventable causes of premature death and disability in the USA. Lancet. 2014;384(9937):45-52. https://doi.org/10.1016/S0140-6736(1014)60648-60646 Epub 62014 Jul 60641.

16. Haskell WL, Blair SN, Hill JO. Physical activity: health outcomes and importance for public health policy. Prev Med. 2009;49(4):280-2. https://doi. org/10.1016/jypmed200910051002 Epub 6402009 May 1020.

17. World Health Statistics 2009: Progress Towards the Health-related Millennium Development Goals. Geneva: World Health Organization; 2009

18. Finkelstein EA. National Medical Spending Attributable to Overweight and Obesity: how much, and Who's paying? Health Affairs; 2003.

19. Sturm R. The effects of obesity, smoking, and drinking on medical problems and costs. Health Aff. 2002;21:245-53.

20. Frumkin $H$, Frank LD, Jackson R. Urban sprawl and public Health: designing, planning, and building for healthy communities. Washington, DC: Island Press; 2004

21. Papas MA, Alberg AJ, Ewing R, Helzlsouer KJ, Gary TL, Klassen AC. The built environment and obesity. Epidemiol Rev. 2007;29:129-43.

22. Owen N, Cerin E, Leslie E, Dutoit L, Coffee N, Frank LD, Bauman AE, Hugo G, Saelens BE, Sallis JF. Neighborhood walkability and the walking behavior of Australian adults. Am J Prev Med. 2007;33:387-95.

23. Frank LD, Schmid TL, Sallis JF, Chapman J, Saelens BE. Linking objectively measured physical activity with objectively measured urban form: findings from SMARTRAQ. Am J Prev Med. 2005:28:117-25.

24. Sallis JF, Bowles HR, Bauman A, Ainsworth BE, Bull FC, Craig CL, Sjöström M, De Bourdeaudhuij I, Lefevre J, Matsudo V, et al. Neighborhood environments and physical activity among adults in 11 countries. Am J Prev Med. 2009;36:484-90.

25. Larson NI, Story MT, Nelson MC. Neighborhood environments: disparities in access to healthy foods in the U.S. Am J Prev Med. 2009;36:74-81.

26. Frank LD, Andresen MA, Schmid TL. Obesity Relationships with Community Design, Physical Activity, and Time Spent in Cars. Am J Prev Med. 2004;27: 87-96.

27. Lopez R. Urban sprawl and risk for being overweight or obese. Am J Public Health. 2004:94:1574-9.

28. Saelens BE, Sallis JF, Black JB, Chen D. Neighborhood-based differences in physical activity: an environment scale evaluation. Am J Public Health. 2003; 93:1552-8.

29. Green RS, Smorodinsky S, Kim JJ, Mclaughlin R, Ostro B. Proximity of California public schools to busy roads. (Children 's Health) Proximity of California public schools to busy roads .( Children 's Health ). Education. 2004;61:1-11.

30. van Roosbroeck S, Wichmann J, NaH J, Hoek G, van Wijnen JH, Lebret E, Brunekreef B. Long-term personal exposure to traffic-related air pollution among school children, a validation study. Sci Total Environ. 2006;368:565-73.

31. Frank LD, Kerr J, Rosenberg D, King AC. Physical Activity and obesity relationships with Community Design in Older Americans. J Phys Act Health. 2010;7(Suppl 1):S82-90.

32. Clifton KJ, Burnier CV, Akar G. Severity of injury resulting from pedestrianvehicle crashes: what can we learn from examining the built environment? Transp Res Part D: Transp Environ. 2009;14:425-36.

33. Ewing $R$, Ra $S$, Zegeer CV. Urban sprawl as a risk factor in motor vehicle occupant and pedestrian fatalities. Am J Public Health. 2003;93:1541-5.

34. Wood L, Frank LD, Giles-Corti B. Sense of community and its relationship with walking and neighborhood design. Soc Sci Med. 2010;70:1381-90.

35. Berke EM, Koepsell TD, Moudon AV, Hoskins RE, Larson EB. Association of the built environment with physical activity and obesity in older persons. Am J Public Health. 2007;97:486-92.

36. Witten K. Geographies of Obesity: Environmental Understandings of the Obesity Epidemic; 2016. 
37. Feng J, Glass TA, Curriero FC, Stewart WF, Schwartz BS. The built environment and obesity: a systematic review of the epidemiologic evidence. Health Place. 2010;16(2):175-90. https://doi.org/10.1016/ jhealthplace200910091008 Epub 2009 Oct 1012.

38. Geiss LS, Wang J, Cheng YJ, Thompson TJ, Barker L, Li Y, Albright AL, Gregg EW. Prevalence and incidence trends for diagnosed diabetes among adults aged 20 to 79 years, United States, 1980-2012. JAMA 2014. 312(12):1218-26. https://doi.org/10.1001/jama.2014.11494.

39. Physical Activity: Built Environment Approaches Combining Transportation System Interventions with Land Use and Environmental Design [https:// www.thecommunityguide.org/findings/physical-activity-built-environmentapproaches].

40. Sallis JF, Floyd MF, Rodriguez DA, Saelens BE. Role of built environments in physical Activity, obesity, and cardiovascular disease. Circulation. 2012;125(5): 729-37.

41. Ferdinand AO, Sen B, Rahurkar S, Engler S, Menachemi N. The relationship between built environments and physical activity: a systematic review. Am J Public Health. 2012;102(10):e7-e13.

42. MacDonald JM, Stokes RJ, Cohen DA, Kofner MS, Ridgeway GK. The Effect of Light Rail Transit on Body Mass Index and Physical Activity. Am J Prev Med. 2010;39(2):105-112. https://doi.org/10.1016/j.amepre.2010.03.016.

43. O'Keeffe-Rosetti MC, Hornbrook MC, Fishman PA, Ritzwoller DP, Keast EM, Staab J, Lafata JE, Salloum R. A standardized relative resource cost model for medical care: application to cancer control programs. J Natl Cancer Inst Monogr. 2013;2013(46):106-16. https:/doi.org/10.1093/jncimonographs/lgt1002.

44. Charlson ME, Pompei P, Ales KL, Mackenzie CR. A new method of classifying prognostic comorbidity in longitudinal studies: development and validation. J Chronic Dis. 1987;40(5):373-83.

45. Rose M, Bjorner JB, Becker J, Fries JF, Ware JE. Evaluation of a preliminary physical function item bank supported the expected advantages of the patient-reported outcomes measurement information system (PROMIS). J Clin Epidemiol. 2008;61(1):17-33.

46. Cella D, Riley W, Stone A, Rothrock N, Reeve B, Yount S, Amtmann D, Bode R, Buysse D, Choi S, et al. The patient-reported outcomes measurement information system (PROMIS) developed and tested its first wave of adult self-reported health outcome item banks: 2005-2008. J Clin Epidemiol. 2010; 63(11):1179-94.

47. Frank LD, Levine J, Chapman J. Transportation and land-use preferences and Atlanta Residents' neighborhood choices. In: Implementing Transit Oriented Development in the Atlanta Region: Georgia Regional Transportation Authority; 2004.

48. Leslie E, Saelens B, Frank L, Owen N, Bauman A, Coffee N, Hugo G. Residents' perceptions of walkability attributes in objectively different neighbourhoods: a pilot study. Health Place. 2005;11(3):227-36.

49. Grosch JW, Alterman T, Petersen MR, Murphy LR. Worksite health promotion programs in the U.S.: factors associated with availability and participation. American journal of health promotion. 1998;13(1):36-45.

50. Linnan L, Bowling M, Childress J, Lindsay G, Blakey C, Pronk S, Wieker S, Royall P. Results of the 2004 National Worksite Health Promotion Survey. Am J Public Health. 2008;98(8):1503-9.

51. John D, Freedson P. ActiGraph and Actical physical activity monitors: a peek under the hood. Med Sci Sports Exerc. 2012;44(1 Suppl 1):S86-9.

52. John D, Tyo B, Bassett DR. Comparison of four ActiGraph accelerometers during walking and running. Med Sci Sports Exerc. 2010;42(2):368-74.

53. Brage S, Wedderkopp N, Franks PW, Andersen LB, Froberg K. Reexamination of validity and reliability of the CSA monitor in walking and running. Med Sci Sports Exerc. 2003;35(8):1447-54

54. Troped PJ, Wilson JS, Matthews CE, Cromley EK, Melly SJ. The built environment and location-based physical activity. Am J Prev Med. 2010; 38(4):429-38.

55. Pucher J, Buehler R, Merom D, Bauman A. Walking and cycling in the United States, 2001-2009: evidence from the National Household Travel Surveys. Am J Public Health. 2011;101(Suppl 1):S310-7.

56. Manson JE, Stampfer MJ, Colditz GA, Willett WC, Rosner B, Speizer FE, Hennekens $\mathrm{CH}$. A prospective study of aspirin use and primary prevention of cardiovascular disease in women. JAMA. 1991;266:521-7.

57. Schuessler N, Axhausen KW. Processing raw data from global positioning systems without additional information. Transp Res Rec. 2015;2009:28-36.

58. Stopher P, FitzGerald C, Zhang J. Search for a global positioning system device to measure personal travel. Trans Research Part C Emerging Technology. 2008;16(3):350-69.
59. Kerr J, Duncan S, Schipperijn J. Using global positioning systems in health research: a practical approach to data collection and processing. Am J Prev Med. 2011:41(5):532-40.

60. Transdermal Nicotine Study Group: Transdermal nicotine for smoking cessation. Six-month results from two multicenter controlled clinical trials. JAMA. 1991;266:3133-8.

61. Frank LD, Sallis JF, Saelens BE, Leary L, Cain K, Conway TL, Hess PM. The development of a walkability index: application to the neighborhood quality of life study. Br J Sports Med. 2010;44:924-33.

62. Frank LD, Fox EH, Ulmer JM, Chapman JE, Kershaw SE, Sallis JF, Conway TL, Cerin $\mathrm{E}$, Cain $\mathrm{KL}$, Adams MA, et al. International comparison of observationspecific spatial buffers: maximizing the ability to estimate physical activity. Int J Health Geogr. 2017;16(1):4. https://doi.org/10.1186/s12942-1201710077-12949.

63. Brownson RC, Hoehner CM, Day K, Forsyth A, Sallis JF: Measuring the built environment for physical activity: state of the science. Am J Prev Med 2009, 36(4 Suppl):S99-123.e112. doi: 1https://doi.org/10.1016/j. amepre.2009.1001.1005.

64. Forsyth A, Van Riper D, Larson N, Wall M, Neumark-Sztainer D. Creating a replicable, valid cross-platform buffering technique: the sausage network buffer for measuring food and physical activity built environments. Int J Health Geogr. 2012;11:14. https://doi.org/10.1186/1476-1072X-1111-1114.

65. Boarnet MG, Forsyth A, Day K, Oakes JM. The street level built environment and physical Activity and walking: results of a predictive validity study for the Irvine Minnesota inventory. Environ Behav. 2011;43(6):735-75.

66. Millstein RA, Cain KL, Sallis JF, Conway TL, Geremia C, Frank LD, Chapman J, Van Dyck D, Dipzinski LR, Kerr J, et al. Development, scoring, and reliability of the Microscale Audit of Pedestrian Streetscapes (MAPS). BMC Public Health. 2013;13:403. https://doi.org/10.1186/1471-2458-1113-1403.

67. Cain KL, Geremia CM, Conway TL, Frank LD, Chapman JE, Fox EH, Timperio A, Veitch J, Van Dyck D, Verhoeven $H$, et al. Development and reliability of a streetscape observation instrument for international use: MAPS-global. Int J Behav Nutr Phys Act. 2018;15(1):19. https://doi.org/10. 1186/s12966-12018-10650-z.

68. Cain KL, Millstein RA, Sallis JF, Conway TL, Gavand KA, Frank LD, Saelens BE, Geremia CM, Chapman J, Adams MA et al: Contribution of streetscape audits to explanation of physical activity in four age groups based on the Microscale Audit of Pedestrian Streetscapes (MAPS). Soc Sci Med 2014, 116:82-92.(doi):https://doi.org/10.1016/ jsocscimed201410061042 Epub 2014 Jun 1024.

69. Sallis JF, Cain KL, Conway TL, Gavand KA, Millstein RA, Geremia CM, Frank LD, Saelens BE, Glanz K, King AC. Is Your Neighborhood Designed to Support Physical Activity? A Brief Streetscape Audit Tool. Prev Chronic Dis. 2015;12:E141. https://doi.org/10.5888/pcd5812.150098.

70. Wagner AK, Soumerai SB, Zhang F, Ross-Degnan D. Segmented regression analysis of interrupted time series studies in medication use research. J Clin Pharm Ther. 2002;27(4):299-309.

71. Simon SR, Smith DH, Feldstein AC, Perrin N, Yang $X$, Zhou Y, Platt R, Soumerai SB. Computerized prescribing alerts and group academic detailing to reduce the use of potentially inappropriate medications in older people. J Am Geriatr Soc. 2006;54(6):963-8.

72. Schoner J, Chapman J, Brookes A, MacLeod K, Fox E, Iroz-Elardo N, Frank L. Bringing health into transportation and land use scenario planning: creating a National Public Health Assessment Model (N-PHAM). Journal of Transportation and Health Forthcoming.

73. Health UD. Health Monetization of Active Transportation; 2016.

74. Frank $L$. Economic determinants of urban form: resulting trade-offs between active and sedentary forms of travel. Am J Prev Med. 2004;27(3S):7.

75. Ewing R, Cervero R. Travel and the built environment: a meta-analysis. J Am Plan Assoc. 2010;76(3):29. 